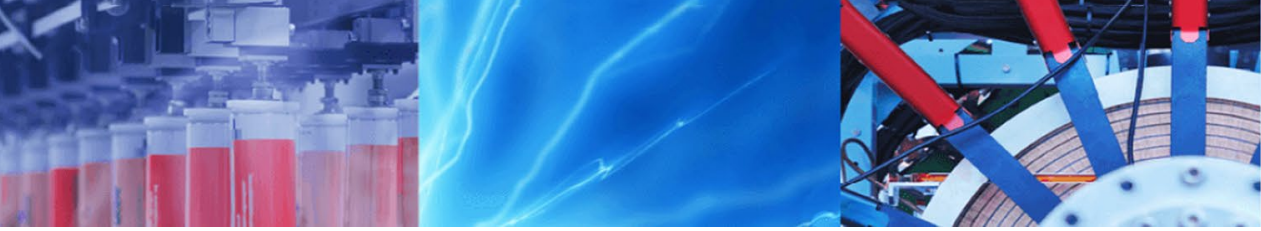

Research Article

\title{
Preparation and adsorption performance evaluation of activated carbon fibers derived from rayon
}

\author{
Tsuyoshi Yoda ${ }^{1,2}$ (1) $\cdot$ Keita Shibuya ${ }^{3} \cdot$ Hideki Myoubudani $^{3}$
}

(c) Springer Nature Switzerland AG 2019

\begin{abstract}
Activated carbon fiber (ACF) is a material that has attracted significant attention because ACFs derived from several fiber sources have been adapted as filter materials. Here, we described successful ACF preparation via single- and two-step thermal treatments of rayon. Methylene blue adsorption abilities of the resulting ACFs were evaluated. Results indicated that ACFs derived from rayon which is prepared by the two-step thermal treatment demonstrate adsorption ability. Moreover, the average gray-scale intensities (Gls) of the carbonized samples were obtained from images captured with a common digital camera, and the results exhibited meaningful correlations for both yield and absorption ability with $\mathrm{Gl}$. Correlation between $\mathrm{Gl}$ and absorption ability suggests the potential for a simple, nondestructive method of evaluating the absorption ability of ACFs. Results obtained for rayon is easily transferred to other fiber products or industrial waste materials generated during the manufacture of textiles that offers potential energy savings.
\end{abstract}

Keywords Activated carbon fiber · Rayon · Adsorption · Thermal treatment

\section{Introduction}

Carbon related materials such as carbon nanotubes are focused as their electronic properties [1, 2]. Recently, activated carbon fibers (ACFs) are known as carbon related materials. ACFs derived from several fiber sources have been adapted as filter materials [3, 4]. ACFs exhibit strong adsorption performance, which is generally higher than that of conventional activated carbon [3-5]. Several methods for the preparation of ACFs, such as chemical modification and heat treatment have been studied; however, the adsorption abilities of ACFs could be potentially improved by ACF preparation methods. Rayon is a well-known synthetic fiber widely used in the production of textiles that has served as a focus of ACFs [6].

Recently, the activation of several different types of carbon sources has also been evaluated [7-9]. Our group has focused on waste materials from clothes. Clothes are made from many kinds of fibers such as cotton, silk polyesters, rayon, and so on. We reported producing activated carbon fibers from silk, cotton and polyester and fiber mixtures from cotton, polyester, and rayon [10-13]. Because rayon is a textile fiber, it is expected to be obtainable as a recycled material. It has been reported that the amount of refuse fiber materials in Japan is approximately $1,712,000 \mathrm{t}$ per year [14]. The productions of ACFs derived from recycled rayon fibers can serve to decrease the burden associated with this refuse and result in substantial energy savings.

Common evaluation procedures for ACF adsorption performance involve methods such as methylene blue (MB) adsorption [15-17], nitrogen adsorption [8, 18] and iodine [19] conventionally. Generally, the process of making ACFs need some steps and spent time, such investigation processes for ACF adsorption performance

Tsuyoshi Yoda, s0830083@hotmail.co.jp | ${ }^{1}$ Chuetsu Technical Support Center, Industrial Research Institute of Niigata Prefecture, 4-1-14 Shinsan, Nagaoka, Niigata, Japan. ${ }^{2}$ Aomori Prefectural Industrial Technology Research Center, Hirosaki Industrial Research Institute, 1-1-8 Ougi-machi, Hirosaki, Aomori, Japan. ${ }^{3}$ Material Applied Technical Assistance Center, Industrial Research Institute of Niigata Prefecture, 2-7-13 School-town, Mitsuke, Niigata, Japan. 
should consume some samples of ACFs. It is expected to investigate the performance without sample consumption. Therefore, we have tried to develop the evaluation of absorption ability for ACF in non-destroy evaluation systems referring to other research [20] using XRF [10]. We also have tried another non-destroying methods for ACFs using common digital camera [10-12] referring to other group which tried to evaluate produced era for important old traditional materials [21, 22].

In this study, we prepared ACFs from rayon using two thermal treatment processes with varying parameters, and the MB adsorption of the resulting samples was evaluated.

Such methods have a shorter point because the sample consumptions were needed.

ACFs with good adsorption performance from rayon fiber could be successfully obtained. Moreover, the average gray-scale intensities (Gls) of the carbonized samples were obtained from images captured with a common digital camera, and the results exhibited meaningful correlations for both yield and absorption ability with $\mathrm{Gl}$. The correlation between $\mathrm{Gl}$ and absorption ability suggests the potential for a simple, nondestructive method of evaluating the absorption ability of ACFs.

\section{Materials and methods}

\subsection{Materials}

Rayon was purchased from the Japanese Standards Association. Cotton was obtained from Nittobo Niigata Co, Ltd. MB, potassium dihydrogen phosphate, and disodium hydrogen phosphate were purchased from Kanto Chemical (Japan). Activated charcoal made from waste palm shell (ACP) was purchased from Taihei Chemical (Japan).

\subsection{Thermal treatment}

The cotton samples were carbonized in a tubular furnace (ISUZU, KRO-14) at various temperatures using a temperature control unit (CHINO, MODEL-SU) under the flow of nitrogen or carbon dioxide gas. It needs around $2 \mathrm{~h}$ in increasing temperature and it was kept an hour on the maximum temperature. Thermal treatments for the activation all conducted at $900^{\circ} \mathrm{C}$ in carbon dioxide gas (Tables 1 and 2). In advance, the samples were prepared from rayon or carbonized carbon by heat treatment from 400 to $600^{\circ} \mathrm{C}$ in nitrogen.

\subsection{Observation}

The structural characteristics of each sample were examined using a scanning electron microscope (SEM; JEOL,
Table 1 Summary of the primary heat treatment processes employed

\begin{tabular}{lll}
\hline Materials & Heat treatment $\left({ }^{\circ} \mathrm{C}\right)$ & $\begin{array}{l}\text { Product } \\
\text { (sample } \\
\text { name) }\end{array}$ \\
\hline Rayon (R) & $\begin{array}{l}\text { Nitrogen gas R.T-900 } \\
\text { Carbon dioxide gas } 900\end{array}$ & R-900C \\
& Nitrogen gas R.T-400 & R-400N \\
& Nitrogen gas R.T-500 & R-500N \\
& Nitrogen gas R.T-600 & R-600N \\
\hline
\end{tabular}

JSM-6060A) [13, 23-25]. The images were processed using Image J software.

\subsection{Adsorption of MB}

Test methods for activated carbon given were referred in Japan Industrial Standard K-1474. Briefly, we began with a $1200 \mathrm{mg} / \mathrm{L}$ aqueous MB solution. Diluted the MB solution with a phosphate buffer was made from potassium dihydrogen phosphate, disodium hydrogen phosphate, and Milli-Q pure water to concentrations of $120,24,12$, $2.4,1.2,0.24$, and $0.12 \mathrm{mg} / \mathrm{L}$. The optical absorbance of these solutions was measured using a spectrophotometer (U-3210, HITACHI, Japan) to obtain a calibration curve. The absorbance of the $120 \mathrm{mg} / \mathrm{L} \mathrm{MB}$ solution was measured after adding $1 \mathrm{~g}$ of $\mathrm{ACF}$, or $\mathrm{ACP}$ as a positive control, and shaking for 30 min by using vibration instrument (TAITEC, Saitama, Japan). Then absorption ability as the amount of $\mathrm{MB}(\mathrm{mg})$ adsorbed was calculated by the activated carbon absorbent (ACF or ACP [g]) based on the optical absorbance of the solution using the obtained calibration curve.

\subsection{Simple evaluation of adsorption performance of ACFs}

The adsorption performances of ACFs were also evaluated without the use of the spectrophotometer using images captured by a digital camera (Ricoh, caplioR5, lens focal length 4.6-33 $\mathrm{mm}$ ) and subsequent processing using Image J software. The samples were photographed at a camera lens-to-sample distance of $30 \mathrm{~cm}$. The method was based on previous methods used in the evaluation of liquid crystals [26-28] and ACFs derived from silk [10], cotton [13], polyester [11], and fiber mixture [12]. The color images were converted to gray-scale with pixel values from 1 to 255 using Image J software, and the average Gl was used to quantify changes in the optical absorbance [10-12]. The average intensity was calculated based on more than 100 points from the gray-scale image. 


\subsection{Statistical tools}

The correlation coefficient and standard deviation were calculated using the CORREL and STDEVP functions, respectively, incorporated into Microsoft Excel 2011.

\section{Results and discussion}

\subsection{Sample labeling}

Typical photos of the untreated and treated rayon $(R)$ samples are shown in Figs. 1 and 2, respectively, and a summary of the heat treating processes employed are listed in Table 1. Figure 1 presents sample images of untreated rayon $(a ; R)$ and rayon heat-treated under carbon dioxide at $900^{\circ} \mathrm{C}(\mathrm{b} ; \mathrm{R}-900 \mathrm{C})$. Figure 2 presents rayon samples heat-treated in nitrogen at $400{ }^{\circ} \mathrm{C}(\mathrm{a} ; \mathrm{R}-400 \mathrm{~N})$, $500{ }^{\circ} \mathrm{C}$ (b; R-500N), and $600^{\circ} \mathrm{C}(\mathrm{c} ; \mathrm{R}-600 \mathrm{~N})$. In addition, as listed in Table 2 , sample $\mathrm{R}-400 \mathrm{~N}$ was subjected to secondary heat treatment in carbon dioxide at $900{ }^{\circ} \mathrm{C}$ (R-400N-900C), sample R-500N heat-treated in carbon dioxide at $900{ }^{\circ} \mathrm{C}$ (R-500N-900C), and sample R-600N heat-treated in carbon dioxide at $900^{\circ} \mathrm{C}$ (R-600N-900C). For comparison, a cotton sample (NC) was heat-treated in nitrogen at $400^{\circ} \mathrm{C}$ (NC-400N), as shown in Fig. 4.

A

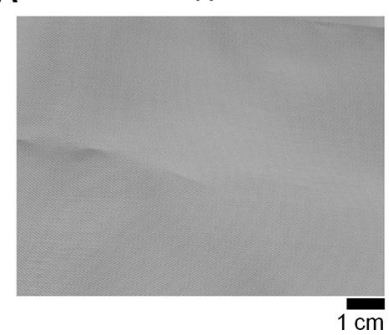

Fig. 1 Images of rayon (a; R) and activated carbon fibers derived from rayon (b; R-900C; Table 1)

Fig. 2 Images of carbonized fibers derived from rayon by heat treatment under nitrogen at several temperatures $(\mathrm{R}-400 \mathrm{~N}(\mathbf{a}), \mathrm{R}-500 \mathrm{~N}(\mathbf{b})$, and R-600N (c); Table 1)
B

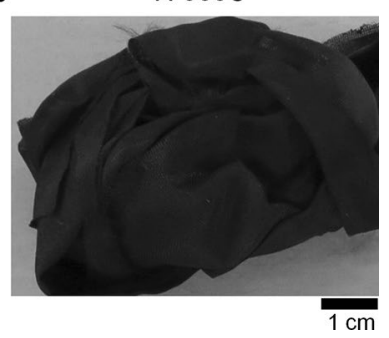

Table 2 Summary of the heat treatment processes employed in the second processing step

\begin{tabular}{lll}
\hline Materials & Heat treatment $\left({ }^{\circ} \mathrm{C}\right)$ & Product (sample name) \\
\hline R-400N & $\begin{array}{l}\text { Nitrogen gas R.T-900 } \\
\text { Carbon dioxide gas } 900\end{array}$ & R-400N-900C \\
& $\begin{array}{l}\text { Nitrogen gas R.T-900 } \\
\text { R-500N }\end{array}$ & R-500N-900C \\
& Carbon dioxide gas 900 & \\
R-600N & Nitrogen gas R.T-900 & R-600N-900C \\
& Carbon dioxide gas 900 & \\
\hline
\end{tabular}

\subsection{Thermal treatment for carbonization}

We first present the results of the ACF derived from rayon. ACF was successfully obtained in a single step by heat treatment at $900^{\circ} \mathrm{C}$ in carbon dioxide (Fig. 1).

Next, ACFs were prepared from the rayon samples by a two-step thermal treatment because two-step heat-treatment of cotton has been shown to yield high adsorption performance. Cotton is known to carbonize by thermal treatment in nitrogen at $400^{\circ} \mathrm{C}$, and because both cotton and rayon mainly consist of cellulose, an equivalent treatment was expected to carbonize rayon as well. However, as shown in Fig. 2a, numerous white regions are observed on the rayon sample, indicating incomplete carbonization. Therefore, the heat treatment temperature was raised to $500^{\circ} \mathrm{C}$ and $600{ }^{\circ} \mathrm{C}$. As indicated by Fig. $2 \mathrm{~b}$, c, respectively, the sample was not fully carbonized at $500{ }^{\circ} \mathrm{C}$, but that heat treatment at $600^{\circ} \mathrm{C}$ resulted in a completely black sample. The average Gls of the rayon samples was also investigated, as shown in Fig. 3, where a low value is indicative of strong black, and consequently, a high degree of carbonization [10-12]. This suggests that the valuable evidence of carbonization can be obtained simply by visual inspection.

The condition of carbonization of rayon with that of cotton was compared. Previously, we reported ACF preparation from cotton purchased from the Japanese Standards Association. This study employed the cotton sample shown in Fig. 4a made from a different weave obtained elsewhere. However, the cotton sample employed in this study was found to be completely carbonized at $400{ }^{\circ} \mathrm{C}$, as
A

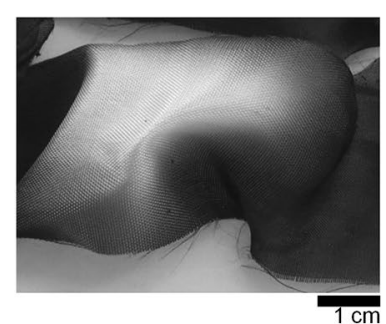

B

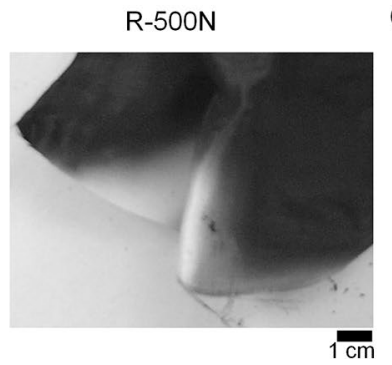

C

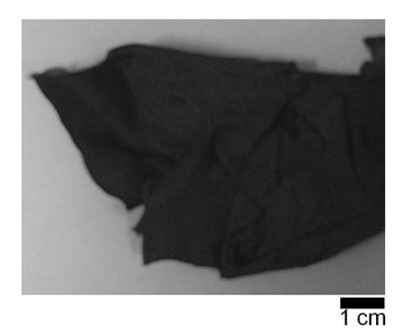

SN Applied Sciences a SPRINGER NatURE journal 


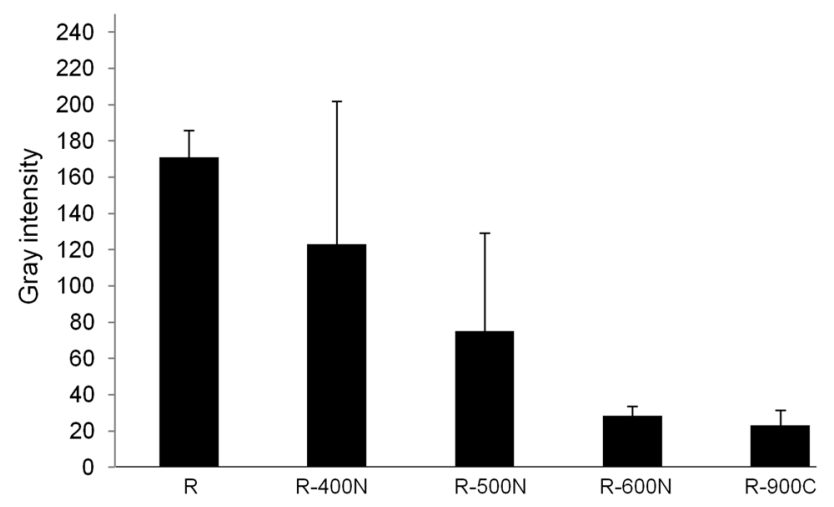

Fig. 3 Average gray-scale intensities of untreated rayon (R) and rayon treated at several temperatures (R-400N, R-500N, R- $600 \mathrm{~N}$, and R-900C; Table 1) based on more than 100 points from the image of each sample; the error bars represent the standard deviation of the measurements
A

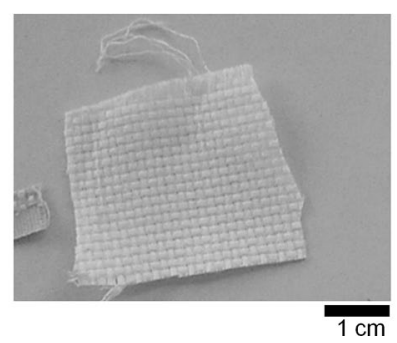

A

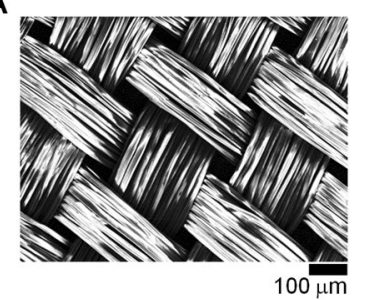

C

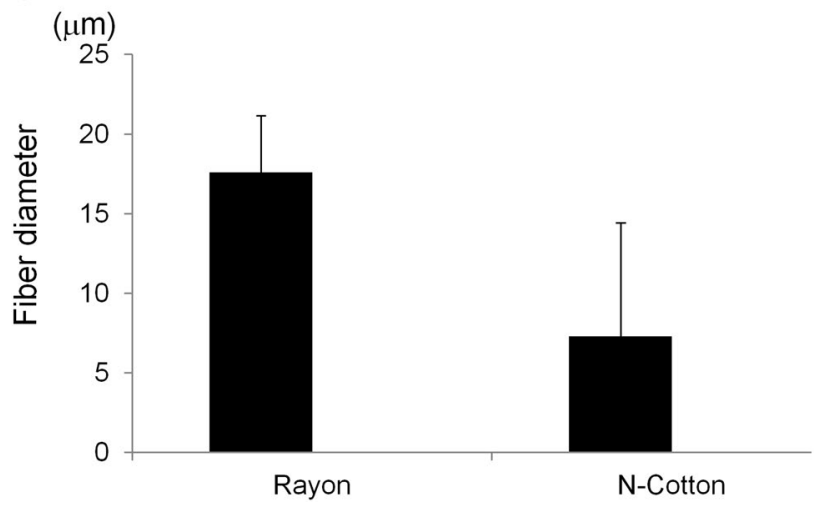

B

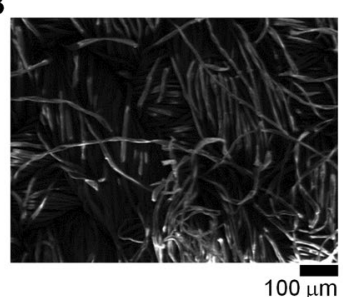

Fig. 6 Typical SEM images of rayon (a) and cotton (b), and their average fiber diameters obtained from the images (c); the error bars represent the standard deviation of the measurements

The untreated rayon and cotton samples were examined using SEM, as shown in Fig. 6a, b, respectively, and the SEM images were employed to determine the respective fiber diameters. For each sample, the diameters of more than 30 fibers were measured, and the calculated averages and standard deviations of the fiber diameters are shown in Fig. 6. It was found that the fibers of both samples mainly consist of cellulose, and the average diameter of the cotton fibers was significantly smaller than that of the rayon fibers. It was tried to compare the degree of carbonization using $\mathrm{Gl}$, because $\mathrm{Gl}$ values may be the index of carbonization of fibers. Gl value of the cotton sample at $400{ }^{\circ} \mathrm{C}$ was almost equivalently to $\mathrm{Gl}$ for rayon derived by heat treatment at $600^{\circ} \mathrm{C}$ (Fig. 5). These results may be based on the property of surface area on each fiber. A larger diameter indicates that each fiber has a larger surface area, and the larger surface area of the rayon fibers is the likely cause of the higher temperature required to carbonize the rayon samples relative to that of the cotton sample.

\subsection{Thermal treatment for activation}

Thermal treatments for the activation of carbonized rayon were all conducted at $900{ }^{\circ} \mathrm{C}$ in carbon dioxide gas (Table 2). In advance, carbonized samples were prepared from rayon by heat treatment from 400 to $600{ }^{\circ} \mathrm{C}$ in 
Fig. 7 Images of activated carbonized fibers subjected to secondary treatment at $900^{\circ} \mathrm{C}$ in carbon dioxide ( $\mathrm{R}-400 \mathrm{~N}-$ $900 \mathrm{C}(\mathbf{a}), \mathrm{R}-500 \mathrm{~N}-900 \mathrm{C}(\mathbf{b})$, and R-600N-900C (c); Table 2)

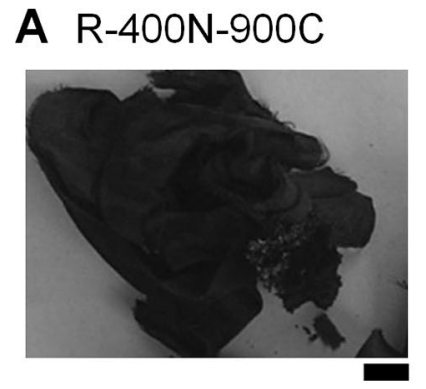

$1 \mathrm{~cm}$

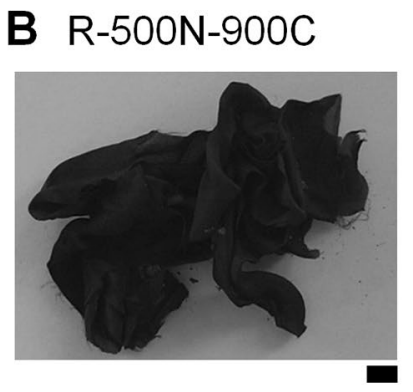

$1 \mathrm{~cm}$
C R-600N-900C

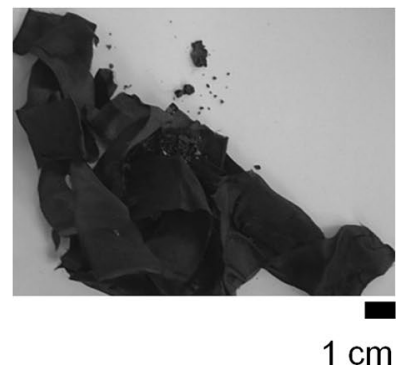

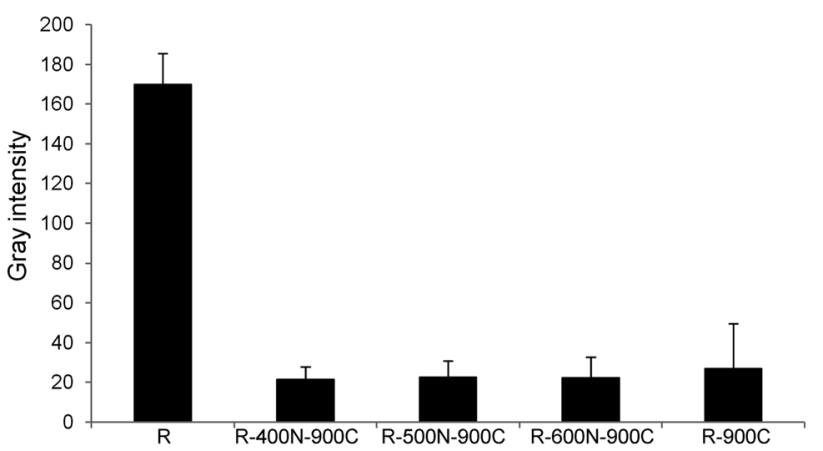

Fig. 8 Average gray-scale intensities of untreated rayon (R), rayon subjected to secondary treatment at $900{ }^{\circ} \mathrm{C}$ in carbon dioxide (R-400N-900C, R-500N-900C, and R-600N-900C; Table 2), and rayon subjected to primary treatment alone (R-900C; Table 1) based on more than 100 points from the image of each sample; the error bars represent the standard deviation of the measurements

nitrogen. These samples were used to prepare the ACFs. As shown in Fig. 7, all samples were fully black, where their Gls are shown in Fig. 8.

\subsection{Sample yields}

The samples yields, which were calculated with the method used by Martinez et al. [29], were 16.05\%, 17.14\%, $11.27 \%$, and $16.80 \%$ for samples R-900C, R- $400 \mathrm{~N}-900 \mathrm{C}$, R-500N-900C, and R-600N-900C, respectively, as shown in Fig. 9. Yields of activated carbon from cotton, walnut shells, and peach stones [29] have been reported to be $37.92 \%$, $20.80 \%$, and $22.2 \%$, respectively. The yields obtained in this study were therefore not improved compared with the previously obtained result for cotton. For the processing of both $R$ to $R-900 C$ and $R$ to $R-600 N$, the sample volumes decreased (Fig. 9), and the sample colors changed to strong black (Figs. 2, 3). Similarly, for the processing of both R-400N to R-400N-900C and R-500N to R-500N-900C, the sample volumes decreased (Fig. 9) and the sample colors changed to strong black (Fig. 6). Conversely, for the processing of R to R-400N and R to R-500N, neither the color (Fig. 2) nor volume (Fig. 9) changed to the same

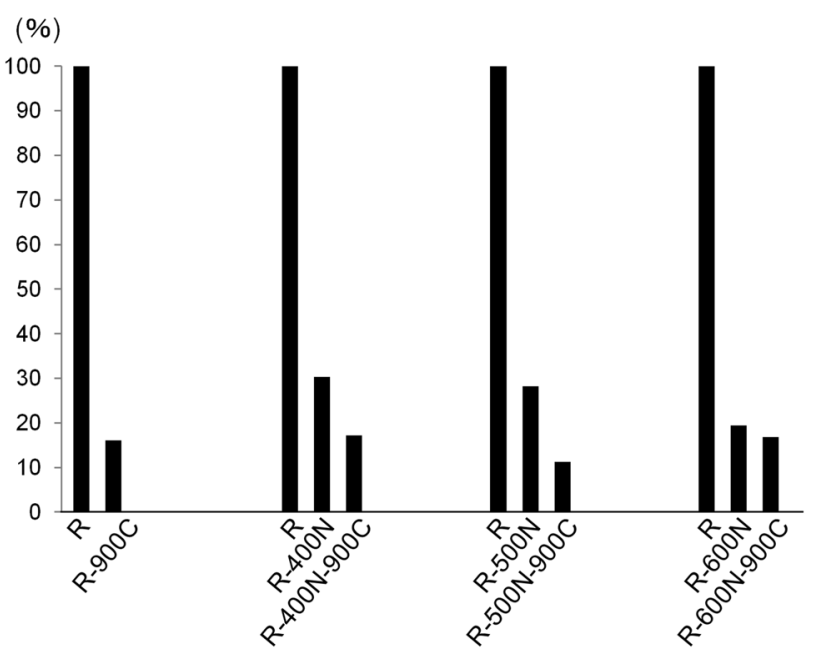

Fig. 9 Activated carbon fibers with corresponding yields (R-900C R-400N, R-400N-900C, R-500N, R-500N-900C, R-600N, and R-600N900C; Tables 1 and 2)

extent as the other cases. These facts indicate that the change of the color to that of strong black and a dramatically decreasing volume were correlated. The correlation coefficient between the Gls and the yields was calculated $(r=0.88)$ verifying the high degree of correlation between the two phenomena.

\subsection{Adsorption}

MB was chosen in this study because it is known to strongly adsorb on activated carbon materials [10-13, 15-17, 25]. The typical adsorption isotherms of $M B$ obtained for ACP, R, R-900C, R400N-900C, R500N-900C, and R600N-900C are shown in Fig. 10. As shown in the figure, the adsorption obtained for samples R-400N-900C and $\mathrm{R}-600 \mathrm{~N}-900 \mathrm{C}$ is nearly equivalent to that of $\mathrm{ACP} . \mathrm{MB}$ adsorption values of ACFs derived from rayon by the twostep treatment were all greater than those obtained for the one-step preparation (R-900C). As was previously found for cotton, this study finds that the two-step thermal treatment is an effective method for the preparation of ACFs 


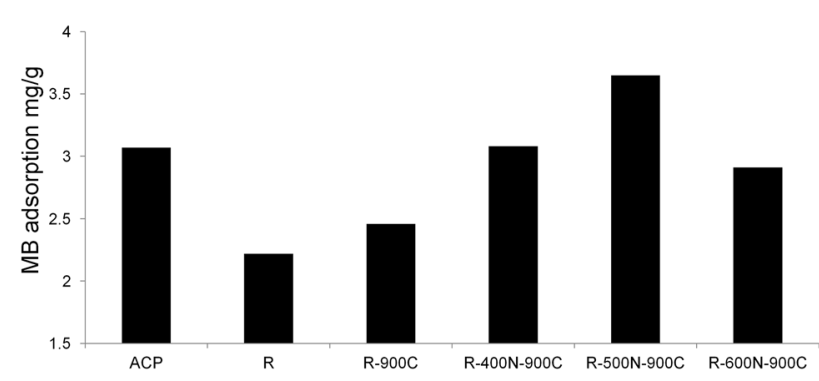

Fig. 10 Methylene blue (MB) adsorption for activated charcoal made from waste palm shell (ACP) rayon (R), and activated carbon fibers (R-900C, R-400N-900C, R-500N-900C, and R-600N-900C; Tables 1 and 2) with an initial MB concentration of $120 \mathrm{mg} / \mathrm{L}$ and an initial sample weight of $1 \mathrm{~g}$

derived from rayon. These results also indicate that the optimum temperature in the first step for good carbonization is approximately $500^{\circ} \mathrm{C}$ because the $\mathrm{MB}$ adsorption of R-500N-900C was the highest of all prepared ACFs.

According to the above results, the ACF products derived from rayon by the two-step thermal treatment process demonstrate superior adsorption ability. The observed high adsorption performance indicates that the pore structure of these samples is well developed with a large surface area. The facts suggest that the two-step thermal treatment might be an efficient method to prepare ACFs for application to electric capacitors because activated carbon with smaller pores exhibits a higher performance as an electric capacitor. Because rayon is a popular textile material, rayon should be easily obtained from textile waste. Therefore, in the future, rayon may be useful as recycled material for the fabrication of electric capacitors.

\subsection{Simple evaluation of ACF absorption ability}

A simple, nondestructive evaluation method of ACF absorption ability would be of great benefit. However, MB adsorption methods used some sample of ACF [10-13, $15-17,25]$. Therefore, it was attempted to evaluate the ACF absorption ability from the GI value based on images obtained using a common digital camera. To evaluate the ACF absorption ability, the correlation between adsorption and the $\mathrm{Gl}$ was calculated. Although the correlation coefficient obtained $(r=0.61)$ was not large, the value indicates that MB adsorption and GI were somewhat correlated. The $\mathrm{Gl}$ is related to light absorbance. It is possible that considerations of wavelength or brightness of the incident light may result in a better correlation. As such, with further development, the method may be useful for the simple evaluation of adsorption ability without sample destruction. Our findings suggest that the evaluation of the adsorption ability of ACFs is possible from simple image analysis.

Conventionally, evaluation procedures for ACF adsorption performance investigated via some methods such as methylene blue (MB) adsorption [15-17], nitrogen adsorption $[8,18]$ and iodine [19]. These methods can directly measure the adsorption ability of ACFs though with sample consumption. ACFs preparation methods need a lot of trying and error even under the obvious strategy. During performance evaluation of ACFs, it will be a shorter point such methods need times and sample consumptions. Therefore, it is the best methods for performance evaluation of ACFs without sample consumptions with a short time. Our proposed methods of camera imaging for ACFs need less than half an hour without sample consumption which is suitable for the above factor even though it needs more improvement for just correlation with actual adsorption value. Therefore, the camera imaging method is a good candidate for characteristic methods for ACFs as non-destroying evaluation in the future.

\section{Conclusion}

It could be that successfully prepared ACFs from rayon fibers using two different heat treatment processes of varying parameters that characterized the products. The results of $\mathrm{MB}$ adsorption experiments revealed that the two-step thermal treatment is a suitable method for ACF preparation. These results may be readily transferred to other fiber waste generated during textile manufacture, and recycled textile fibers may enable significant energy savings. Furthermore, it could be found that the MB adsorption values and the average Gls of the samples were correlated, and we anticipate the possibility of a simple evaluation of the adsorption ability of ACFs without sample destruction.

Acknowledgements The authors thank Mr. Seiji Satou (director of Material Applied Technical Assistance Center Industrial Research Institute of Niigata Prefecture) for reading the manuscript and providing his critical comments. The authors would like to thank springer editor for the English language review. This research did not receive any specific grant from funding agencies in the public, commercial, or not-for-profit sectors.

\section{Compliance with ethical standards}

Conflict of interest The authors have no confict of interest as far as the present study is concerned, to the best of their knowledge.

\section{References}

1. Zhang S, Nguyen N, Leonhardt B, Jolowsky C, Hao A, Park JG, Liang R (2019) Carbon-nanotube-based electrical conductors: 
fabrication, optimization, and applications. Adv Electron Mater 1800811

2. Zhang S, Park JG, Nguyen N, Jolowsky C, Hao A, Liang R (2017) Ultra-high conductivity and metallic conduction mechanism of scale-up continuous carbon nanotube sheets by mechanical stretching and stable chemical doping. Carbon 125:649-658

3. Ekrami E, Dadashian F, Soleimani M (2014) Waste cotton fibers based activated carbon: optimization of process and product characterization. Fibers Polym 15:1855-1864

4. Matovic LL, Vukelic NS, Jovanovic UD, Kumric KR, Krstić JB, Babić BM, Đukic AB (2016) Mechanochemically improved surface properties of activated carbon cloth for the removal of As (V) from aqueous solutions. Arab J Chem. https://doi.org/10.1016/j. arabjc.2016.07.004

5. Zheng J, Zhao Q, Ye Z (2014) Preparation and characterization of activated carbon fiber (ACF) from cotton woven waste. Appl Surf Sci 299:86-91

6. Ikegami D, Hirose $\mathrm{S}$, Katoh $\mathrm{K}$, Manufacturing technology of carbonized fiber. http://www.aichi-inst.jp/mikawa/research/repor t/mikawa_2007_08.pdf. Accessed 7 Apr 2019

7. Özacar M, Şengil IA (2002) Adsorption of acid dyes from aqueous solutions by calcined alunite and granular activated carbon. Adsorption 8:301-308

8. Demiral H, Demiral H (2008) Surface properties of activated carbon prepared from wastes. Surf Interface Anal 40:612-615

9. Jayganesh D, Tamilarasan R, Kumar M, Murugavelu M, Sivakumar V (2017) Equilibrium and modelling studies for the removal of crystal violet dye from aqueous solution using eco-friendly activated carbon prepared from Sargassm wightii seaweeds. J Mater Environ Sci 8:2122-2131

10. Yoda T, Shibuya K, Miura K, Myoubudani H (2017) Characterization of the adsorption ability of silk-derived activated carbon fibers using X-ray analysis and camera imaging methods. Measurement 101:103-110

11. Yoda T, Shibuya K, Myoubudani H (2018) Preparation of activated carbon fibers from mixtures of cotton and polyester fibers. Measurement 125:572-576

12. Yoda T, Shibuya K, Myoubudani H (2018) Preparation of activated carbon fibers from fiber mixtures. J Text Eng and Fashion Tech 1:1-4. https://doi.org/10.33552/JTSFT.2018.01.000510

13. Yoda T, Shibuya K, Miura K, Myoubudani H, Effects of two-step heat treatment on the structure of cotton-derived activated carbon fibres. Int J Mater Struct Integr (in press)

14. Ministry of Economy (2006) Trade and Industry of Japan, 3R SYSTEM KA KANOUSEITYOUSAJIGYOU HAITENNENSENISEIHINTOUNO CASCADING KATSUYOUNIKAKAWARUTYOUSAJIGYOU HOKOKUSYO, (means, "Report on 3R system research project related to cascading of waste natural fiber products") http://www.meti.go.jp/policy/recycle/main/data/research/ h18fy/180403-87_cjc/180403-87_a.pdf

15. Benstoem F, Becker G, Firk J, Kaless M, Wuest D, Pinnekamp J, Kruse A (2018) Elimination of micropollutants by activated carbon produced from fibers taken from wastewater screenings using hydrothermal carbonization. J Environ Manag 211:278-286
16. Chongrak K, Eric H, Noureddine A, Jean P (1998) Application of methylene blue adsorptionto cotton fiber specific surface area measurement. J Cotton Sci 2:164-173

17. Japanese Industrial Standards (JIS) K-1474 (2014) Test methods for activated carbon, characterization for adsorption ability of methylene blue, 7-10

18. Sun J, Satyapal S (1999) Methanol adsorption on activated carbons for adsorption heat pump applications. http://acs.omnib ooksonline.com/data/papers/1999_652.pdf. Accessed 7 Apr 2019

19. Chen W, Zhang S, He F, Lu W, Xv H (2019) Porosity and surface chemistry development and thermal degradation of textile waste jute during recycling as activated carbon. J Mater Cycles Waste Manag 21:315-325

20. van Dalen G (2000) Protein on cloths: evaluation of analytical techniques. Appl Spectrosc 54:1350-1356

21. Yoshida N (2009) A basic study on "digital camera spectroscopy" for identifying color materials. Hozon Kagaku 48:51-59 (in Japanese)

22. Yoshida N (2010) Infrared photography using LED light source. Hozon Kagaku 49:119-124 (in Japanese)

23. Mouri A (2014) Study of structure in cast iron and x-ray fluorescence quatitative analysis. In Report of the Industrial Research Institute of NIIGATA Prefecture vol 43, pp 48-50

24. Yoda T, Mouri A (2015) Surface observation and element distribution of a cupronickel coin. Prot Met Phys Chem Surf 51:710-715

25. Myobudani H, Watanabe R, Kasahara K, Okada H (2014) Report of market and technology trends of activated carbon of cotton. In Report of the Industrial Research Institute of NIIGATA Prefecture vol 43, pp 85-87

26. Lin SY, Ho CJ, Li MJ (2001) Precision and reproducibility of temperature response of a thermo-responsive membrane embedded by binary liquid crystals for drug delivery. J Control Release 73:293-301

27. Brake JM, Daschner MK, Luk YY, Abbott NL (2003) Biomolecular interactions at phospholipid-decorated surfaces of liquid crystals. Science 302:2094-2097

28. Yoda T, Phan HTT, Vestergaard MC, Hamada T, Takagi M (2012) Thermo-induced dynamics of membranes and liquid crystals containing cholesterol derivatives. In 2012 international symposium on IEEE, micro-nanomechatronics and human science (MHS), pp 87-92

29. Martinez ML, Moiraghi L, Agnese M, Guzman C (2003) Making and some properties of activated carbon produced from agricultural industrial residues from argentina. J Argent Chem Soc 91:103-108

Publisher's Note Springer Nature remains neutral with regard to jurisdictional claims in published maps and institutional affiliations. 